University of Wollongong

Research Online

Faculty of Social Sciences - Papers (Archive) Faculty of Arts, Social Sciences \& Humanities

2016

Sequential processing in young and older adults in the equiprobable auditory Go/NoGo task

Robert J. Barry

University of Wollongong, rbarry@uow.edu.au

Frances M. De Blasio

University of Wollongong, francesd@uow.edu.au

Adele E. Cave

University of Wollongong, aec236@uowmail.edu.au

Follow this and additional works at: https://ro.uow.edu.au/sspapers

Part of the Education Commons, and the Social and Behavioral Sciences Commons

Research Online is the open access institutional repository for the University of Wollongong. For further information contact the UOW Library: research-pubs@uow.edu.au 


\title{
Sequential processing in young and older adults in the equiprobable auditory Go/ NoGo task
}

\begin{abstract}
Objective: We recently proposed a sequential processing schema for the equiprobable auditory Go/NoGo task, based on a principal components analysis (PCA) of event-related potentials (ERPs) from a university student sample. Here we sought to replicate the schema, and use it to explore processing in wellfunctioning older adults. Methods: We compared behavioural responding and ERPs of 20 independentliving older adults ( $M a g e=68.2$ years) to data from a sex- and handedness-matched group of university students (Mage $=20.4$ years). ERPs had substantial latency differences between the groups, and hence were subjected to separate group temporal PCAs. Results: Component latencies were systematically increased in the older group by some $26 \%$, with no significant increase in RT or error rates. Despite some differences in their identified components, each group displayed differential component responsivity to Go versus NoGo; this was reduced in the older participants. Conclusion: The results support our processing schema, and provide insight into the processing stages in well-functioning older adults. Significance: Understanding the perceptual and cognitive processing stages in normal ageing is a prerequisite for research on mild cognitive impairment and dementia. This study may also provide a simple paradigm and schema suitable for further exploration of functionality in ageing.
\end{abstract}

\section{Keywords}

young, task, nogo, go, processing, auditory, sequential, equiprobable, adults, older

Disciplines

Education | Social and Behavioral Sciences

\section{Publication Details}

Barry, R. J., De Blasio, F. M. \& Cave, A. E. (2016). Sequential processing in young and older adults in the equiprobable auditory Go/NoGo task. Clinical Neurophysiology, 127 (5), 2273-2285. 
Sequential Processing in Young and Older Adults in the Equiprobable Auditory Go/NoGo Task

Robert J. Barry*, Frances M. De Blasio, Adele E. Cave

Centre for Psychophysics, Psychophysiology, and Psychopharmacology; Brain \& Behaviour Research Institute; and School of Psychology, University of Wollongong, Wollongong NSW 2522, Australia

*Corresponding author

Email: rbarry@uow.edu.au

Phone: +612 42214421 


\section{Highlights}

- A PCA derived sequential processing Go/NoGo schema was confirmed in young adults, with similar processing in healthy older adults.

- Older adults had comparable Go RT and Go/NoGo error rates, increased latencies and smaller, less differentiated Go/NoGo P3s, and N2c was absent.

- Go/NoGo processing by Older adults may reflect less specialist processing regions, requiring more effort. 


\section{ABSTRACT}

Objective: We recently proposed a sequential processing schema for the equiprobable auditory Go/NoGo task, based on a principal components analysis (PCA) of event-related potentials (ERPs) from a university student sample. Here we sought to replicate the schema, and use it to explore processing in well-functioning older adults.

Methods: We compared behavioural responding and ERPs of 20 independent-living older adults $\left(M_{\text {age }}=68.2\right.$ years $)$ to data from a sex- and handedness-matched group of university students $\left(M_{\text {age }}=20.4\right.$ years). ERPs had substantial latency differences between the groups, and hence were subjected to separate group temporal PCAs.

Results: Component latencies were systematically increased in the older group by some $26 \%$, with no significant increase in RT or error rates. Despite some differences in their identified components, each group displayed differential component responsivity to Go versus NoGo; this was reduced in the older participants.

Conclusion: The results support our processing schema, and provide insight into the processing stages in well-functioning older adults.

Significance: Understanding the perceptual and cognitive processing stages in normal ageing is a pre-requisite for research on mild cognitive impairment and dementia. This study may also provide a simple paradigm and schema suitable for further exploration of functionality in ageing.

Key Words: Ageing, Event-related potentials (ERPs), Auditory equiprobable Go/NoGo task, Principal Components Analysis (PCA), Sequential processing schema 


\section{Introduction}

When a signal requiring perceptual and/or cognitive processing is presented, it elicits a series of EEG changes at the scalp that reflect the underlying brain activity. Averaging of these time-locked to the stimulus event leads to the event-related potential (ERP), a series of waveforms considered to represent the summation of several components reflecting the corresponding processing sequence. Experimental decomposition of the ERP into these components allows investigation of their determinants and behavioural correlates. Principal components analysis (PCA) is a variant of factor analysis that is increasingly used in the ERP context to decompose the waveform into such underlying components and sub-components. A detailed exposition is beyond the scope of the present paper, but the interested reader is referred to outlines by Kayser and Tenke (2003) and Dien (2012). In brief, PCA provides a rapid and objective, data-driven decomposition that delivers reproducible outcomes consistent from laboratory to laboratory. Moreover, this technique facilitates the disentanglement of the components and sub-components in the ERP dataset, and thus allows for their independent assessment, offering improved temporal insight. Together these benefits make the PCA quantification of ERP components ideal in the investigation of the sequential processing stages (perceptual and cognitive) of a specific task or paradigm.

The unwarned equiprobable auditory Go/NoGo paradigm has been found useful in a number of brain dynamics studies from our laboratory. This task provides equal numbers of trials in two distinct processing streams (Go vs. NoGo), facilitating subdivision of trials to form ERPs at different levels of prestimulus electroencephalographic (EEG) phase (e.g., Barry and De Blasio, 2012; Barry et al., 2010, 2014c) or amplitude (e.g., De Blasio and Barry, 2013a,b). Subsequently we began a series of studies to increase our understanding of the perceptual- and cognitive-processing stages involved in this simple fixed stimulus onset asynchrony (SOA) task, and their ERP correlates. This resulted in a proposed processing schema (Barry and De Blasio, 2013), based on a PCA decomposition of the ERPs from a university sample of young 
adults.

Our task is midway between the traditional oddball task (with probability: Go/target < NoGo/standard) and the traditional unwarned Go/NoGo task (with probability: Go/target > NoGo/standard), and it shares many similarities with the sequential processing established in these more extreme paradigms. Similar major component peaks are apparent: P1, N1, P3, and the classic Slow Wave (SW), with relative amplitudes varying with the stimulus probabilities (e.g., for P3: Duncan-Johnson and Donchin, 1977; Johnson, 1986). Small P2 and N2 components are usually apparent as inflection points between the N1 and P3 peaks. The major components are generally confirmed in PCA decompositions, with additional separation of some sub-components. For example, we reliably find N1 separating into N1-1 (the dominant “true” N1 component) and the temporal Processing Negativity (PN), as defined by Näätänen and Picton (1987). In addition, Barry and De Blasio (2013) reported a novel NoGo diffuse Late Positivity (LP) after the SW, and this has been confirmed in subsequent studies (Barry et al., 2014a,b,c). The P2/N2 components carry little variance in the PCA decompositions and have been somewhat unstable between studies (Barry and De Blasio, 2015).

In Barry and De Blasio (2013), we found that N1-1 and the defining PN topography were enhanced to Go, and followed by a vertex P2, and N2 and $\mathrm{P} \mathrm{b}^{1}$, and an enhanced SW. NoGo produced what appeared as an enhanced centroparietal P2 with a frontal negativity, a frontocentral N2 and P3a, and a large LP. These results suggested that N1 sub-components mark the beginning of Go and NoGo differentiation, with the P2 and N2 marking complete Go/NoGo categorisation. Subsequent differential processing chains lead to the NoGo nonresponse (marked by P3a) and the effortful Go response (marked by P3b and SW). In NoGo, the larger LP then marks the cortical deactivation following the early cessation of active stimulus processing in this chain. We have since verified the major features of this schema in other samples of young adults (Barry et al., 2014a,b,c). An important conceptual change over these studies is that we now interpret the obtained P2 as a P2/N2b complex, separating into a P2 
in Go (Crowley and Colrain, 2004) and frontal N2 in NoGo (consistent with Huster et al., 2013), and marking the beginning of the separate component chains reflecting the different Go/NoGo neuropsychological processes (see Introduction in Barry and De Blasio, 2015). The following separate N2 component is greater in Go (consistent with Folstein and van Petten, 2008). We now label these Go/NoGo N2s as N2c and N2b respectively, following Pritchard et al. (1991).

The schema is illustrated in Figure 1, redrawn from data in Barry and De Blasio (2013) with updated labels from Barry and De Blasio (2015). PCA-derived components and sub-components are grouped and labelled (panel C) to correspond with the ERP peaks (panel A). The perceptual and cognitive processing stages associated with these are also indicated in panel C.

Fig 1 about here

The simplicity of this equiprobable Go/NoGo task has allowed us to extend the sequential processing schema to children, where we have found a generally comparable processing sequence despite the sometimes substantial differences in task performance and ERP component outcomes (Barry and De Blasio, 2015; Barry et al., 2014a). Now we seek to extend the processing schema to older adults, and use this to help understand the age-related changes in perceptual and cognitive processing in this paradigm.

The impact of healthy ageing on behavioural performance has long been of interest. The large Baltimore longitudinal study of ageing (Fozard et al., 1994) included a behavioural equiprobable Go/NoGo task, and they reported a cross-sectional linear increase in Go reaction time (RT) of 1.6 ms/year from 20 to 90 years; Go omission and NoGo commission errors also increased, as did intra-individual RT variability. These effects are not large, and ERP studies, generally with small young/old groups and differing paradigms, have reported mixed RT results (e.g., comparable: Čeponienė et al., 2008; Polich, 1997; vs. delayed: Falkenstein et al., 2006). Although apparently not explored in the equiprobable Go/NoGo task, ERP component latencies 
tend to show little if any change in the early sensory components such as P1 (when assessed) and N1 (Anguera and Gazzaley, 2011; Beck et al., 1980; Čeponienè et al., 2008; Ford et al., 1979; Goodin et al., 1978; Ho et al., 2012; Pfefferbaum et al., 1980; Yordanova et al., 2004). There have been inconsistent effects in P2 latency (Crowley and Colrain, 2004), and delays in the later cognitive components such as N2 (if assessed) and P3 (Beck et al., 1980; Ford et al., 1979; Goodin et al., 1978; Marsh and Thompson, 1972; Pfefferbaum et al., 1980; Polich, 1997). Goodin et al. (1978) suggested that age-related increases in latency are proportional to the latency of the component.

In terms of amplitudes, generally there have been little or no age effects in P1 (Čeponienė et al., 2008; Yordanova et al., 2004) or N1 (Čeponienė et al., 2008; Ford et al., 1979; Polich, 1997; Yordanova et al., 2004), decreases in N1-P2 (Goodin et al., 1978), equivocal effects in P2 (decrease: Ford et al., 1979; increase: Čeponienè et al., 2008; Pfefferbaum et al., 1980; no effect: Polich, 1997), and decreases in N2 (Čeponienè et al., 2008), N2-P3 (Goodin et al., 1978), and P3 (Ford et al., 1979; Polich, 1997). Topographic changes in the later components have also been noted in some studies, with an increase in equipotentiality (Friedman et al., 1997; Goodin et al., 1978; Pfefferbaum et al., 1980; Polich, 1997). The frontal negativity of the classic SW has also been reported to be absent in an older group (Pfefferbaum et al., 1980). This type of topographic finding has been interpreted increasingly as evidence for compensatory frontal activity in older compared with younger subjects, used to maintain relatively high performance levels (e.g., Hong et al., 2014; Hsieh and Fang, 2012; Staub et al., 2014; Vallesi, 2011) in the context of reductions in frontal brain volume (Driscoll et al., 2009; Raz et al., 2005).

The present study utilises the auditory equiprobable Go/NoGo task to assess and compare the performance and ERP component outcomes between a group of young adults and a group of well-functioning older adults. In the context of the ageing literature, we predict that the young group, to some extent, will outperform the older group in terms of their mean RT, 
and errors of Go omissions and extreme (fast, slow) response times, and NoGo commissions. It is also expected that the older group will show increased intra-individual RT variability. In our young group, we expect to replicate the sequence of components and their differential Go/NoGo profiles described in our processing schema for this paradigm (Barry and De Blasio, 2013, 2015): P1, N1-1, PN, P2/N2b, N2c, P3, SW, and LP. We predict that the older group will show a sequence of ERP components and Go/NoGo effects generally similar to those in the young group. However, increases in component latency proportional to the latency of the component are expected, and differences in component time course may also be seen between the groups. Some differences in component amplitude and topographies are also expected, particularly a decrease in amplitude and increase in the equipotentiality of the later components.

\section{Methods}

\subsection{Participants}

Our young sample contained 20 right-handed university students (5 male/15 female) with an age range of $18.8-25.6(M=20.4, S D=1.6)$ years, who participated as one means of satisfying a course requirement. The older group consisted of 20 hand- and sex-matched independent-living adults in a retirement resort community, with an age range of 59.8-74.8 ( $M$ $=68.2, S D=4.5$ ) years. They were recruited via a flyer and received AUD40 as recompense for their time. All were screened for neurological disorders, serious head injury resulting in unconsciousness or long term impairment, learning disabilities and psychiatric conditions, and abstained from caffeine, tobacco, and other psychoactive substances for $2.5 \mathrm{~h}$ before testing. Additionally, the older participants provided a list of their current medications (including dosage), and completed the Rowland Universal Dementia Assessment Scale (RUDAS), a cognitive screening instrument (Story et al., 2004). All scored $>22(M=28.0, S D=1.5)$, the cut-off for possible cognitive impairment. Participation was voluntary and written informed consent was obtained following a protocol approved by the joint University of 
Wollongong/South East Sydney and Illawarra Area Health Service Human Research Ethics

Committee, in accordance with the Declaration of Helsinki.

\subsection{Physiological recording}

To minimise set-up time, particularly for the older participants, EEG was recorded from A2 and 19 scalp sites using an electrode cap with tin electrodes, referenced to A1. The vertical electro-oculogram (EOG) was recorded from tin electrodes above and below the left eye, and the horizontal EOG from electrodes beyond the outer canthi. All impedances were below $10 \mathrm{k} \Omega$. Data were sampled continuously at $1000 \mathrm{~Hz}$ with a gain of 500, and recorded DC-30 Hz by a Neuroscan Synamps 2 system using Neuroscan Acquire software (Compumedics, Version 4.3.1) for offline analysis.

\subsection{Task and procedure}

We presented four stimulus blocks via circumaural headphones, with brief rest periods interspersed. Each presentation block consisted of 150 tones of 50 ms duration with additional $15 \mathrm{~ms}$ rise and fall times, presented with a fixed SOA of 1,100 ms. The young received $60 \mathrm{~dB}$ SPL tones, while the older adults received $70 \mathrm{~dB}$ SPL tones to ensure audibility given the hearing deficits typical in this population (e.g., Grassi and Borella, 2013). Half the tones were $1000 \mathrm{~Hz}$ (tone A) and half were $1500 \mathrm{~Hz}$ (tone B), with these delivered in a randomised order. The participants were required to button-press to one of the tones; the target frequency alternated between the blocks (i.e., ABAB or BABA), and the frequency of the target tone of the first block was counterbalanced across participants. Participants were asked to maintain gaze fixation on a small cross displayed on a computer monitor (LCD) $1 \mathrm{~m}$ in front of them, and instructed to respond as quickly and accurately as possible to the designated target tone. Each participant also completed a brief EOG calibration task prior to the experiment to facilitate later EOG correction; this involved the participant making a series of vertical and horizontal eye movements, and eye blinks.

\subsection{ERP quantification}


The continuous EEG was EOG corrected using the RAAA procedure (Croft and Barry, 2000), digitally re-referenced to linked ears, and lowpass filtered (24 Hz, zero phase shift, $24 \mathrm{~dB}$ /Octave). Separately for Go and NoGo, epochs (-100 to $+1,000 \mathrm{~ms}$ ) were extracted for trials with correct responding, defined within-subject for Go as a button-press response within $\pm 2 S D$ of the mean of their RTs occurring within the SOA, and for NoGo as no response within the 1,100 ms SOA. Epochs were then baselined (-100 to $0 \mathrm{~ms}$ ), and an automatic artefact rejection procedure rejected epochs if activity at any scalp site exceeded $\pm 100 \mu \mathrm{V}$ at any time in the epoch. Within-subject mean ERPs were derived from the remaining epochs for each condition in each presentation block.

Preliminary examination of the data indicated that the older group had ERP peaks somewhat delayed compared with the young group, and hence separate temporal PCAs were conducted for each group. Epochs were down-sampled to $500 \mathrm{~Hz}$ to reduce computing time. The PCAs had 550 variables and 3040 cases ( 2 conditions $\times 4$ blocks $\times 19$ sites $\times 20$ subjects). These values yielded a cases/variables ratio of 5.5. Each PCA used the covariance matrix with Kaiser normalisation, followed by unrestricted Varimax rotation. The PCAs were conducted in MATLAB (The Mathworks, Version 8.0.0.783, R2012b) using Dien’s (2010) ERP PCA toolkit (v. 2.23) and Kayser and Tenke's (2003) Varimax4M function for the orthogonal rotation (available at http://psychophysiology.cpmc.columbia.edu/software/). The resulting PCA factors were identified as ERP components based on their latency, polarity, topographic distribution, and similarity to components previously identified in this paradigm (Barry and De Blasio, 2013, 2015; Barry et al., 2014a,b,c).

\subsection{Statistical analyses}

Age and performance measures were compared between the groups using one-tailed $t$ tests with $d f$ adjusted for unequal variances. The adequacy of the PCA-generated virtual ERP fit was assessed by correlating the waveform of the mean ERP for each condition at each of the midline sites (Fz, Cz, Pz) with the summed components forming the corresponding 
reconstituted ERP.

Separately for each group (Young, Older), a repeated-measures MANOVA examined the within-subjects effects of Condition (Go vs. NoGo) for each of the identified components, using the component amplitudes at 9 central sites (F3, Fz, F4, C3, Cz, C4, P3, Pz, P4). Each analysis included examination of topography, with sagittal plane [frontal (F3, Fz, F4), central (C3, Cz, C4) and parietal (P3, Pz, P4)] and coronal plane [left (F3, C3, P3), midline (Fz, Cz, Pz) and right (F4, C4, P4)] as within-subjects repeated-measures factors. For the temporally distributed PN (Näätänen and Picton, 1987), we replaced the F3/4, C3/4, P3/4 electrode pairs with F7/8, T7/8, P7/8, respectively. Planned contrasts within the sagittal plane compared frontal (F) vs. parietal (P) regions, and central (C) sites vs. the mean of the frontal and parietal (F/P) sites. Within the coronal plane, the left (L) vs. right $(\mathrm{R})$ regions, and the midline $(\mathrm{M}) \mathrm{vs.}$ the mean of the left and right $(\mathrm{L} / \mathrm{R})$ sites, were analysed. These orthogonal planned contrasts provide optimal information on the topographic distribution of the amplitude of each component. Since all contrasts were planned and there were no more of them than the degrees of freedom for effect, no Bonferroni-type adjustment to $\alpha$ was necessary (Tabachnick and Fidell, 2013). Greenhouse-Geisser type correction was also unnecessary because single degree of freedom contrasts are not affected by the violations of sphericity assumptions common in repeated measures analyses of physiological data (O'Brien and Kaiser, 1985). All F tests reported have $(1,19)$ degrees of freedom. Note that effects approaching significance $(.05<p \leq$ $.10)$ are reported in addition to those that reached significance $(p \leq .05)$, but only the latter are discussed.

We compared components between the groups in terms of peak latency, similarity in component loading, and topography. First, the latencies of the corresponding components were compared between the young and older adult groups using a scatterplot with a linear trend line forced through the origin. Second, to assess the similarity in time course of a component from different PCAs, the Congruence Coefficient $\left(r_{c}\right.$; Tucker, 1951) has been used. This is a form of 
correlation between the unscaled component loadings, but the variables are not standardised, so that both temporal shifts and amplitude differences affect the value. Equality of components is indicated by $r_{c} \geq .95$, and similarity by $.94 \geq r_{c} \geq .85$ (Lorenzo-Seva and ten Berge, 2006). The obvious differences in component latencies between the groups suggested that direct use of $r_{c}$ would largely reflect that latency shift rather than meaningful component comparisons. Therefore, a cubic spline interpolation of the young unscaled factor loadings, based on the linear trend line fitted in the latency comparison, was used to compute "adjusted” Congruence Coefficients across the post-stimulus data points. Third, we compared the groups on the mean (across-subjects) topographic distribution of each corresponding component, correlating the peak amplitudes across the 19 recording sites and Go/NoGo (i.e., $N=38$ ). A two-tailed $\alpha$ level of .05 was required for significance.

\section{Results}

\subsection{Age and performance measures}

For each group, Table 1 shows their mean age, RT (mean and intra-individual variability), omission and extreme RT errors (outside $M \pm 2 S D$ ) to Go stimuli, and commission errors to NoGo stimuli, together with the number of accepted trials included in their ERPs. In comparison to the young adults, the mean age of the older adults was significantly higher, their intra-individual RT variability was significantly increased, their mean RT was somewhat longer, and their number of fast RT errors was somewhat smaller; the last two effects approached significance. None of the remaining variables differed between the groups.

Table 1 about here

\subsection{PCA outcomes}

Figure 2A displays the ERPs at midline sites for the Young group, with the prominent components indicated at Fz. Following a small P1 around 50 ms, there is a noticeable N1 ( 100 ms), then a large central P3a in NoGo ( 250 ms) and a large parietal P3b in Go ( $350 \mathrm{~ms})$. 
These are followed by a frontal-negative/parietal-positive SW around $450 \mathrm{~ms}$, and a NoGo LP. Corresponding ERPs for the Older group are shown in Figure 2C. The dominant N1/P3 pattern is broadly similar to that in the Young group. However, this is preceded by a large P1, and the P3 appears later than in the Young group. Anteriorisation of the NoGo P3a is more apparent than in the young (peaking at Fz rather than $\mathrm{Cz}$ ), but there is no evidence of the classic frontally-negative SW before the LP.

Fig. 2 about here

In the young adults, the first 10 PCA components were identifiable and together explained $87.1 \%$ of the variance. No further components carried more than $0.9 \%$ variance. Correlations between the raw (Figure 2A) and reconstituted (Figure 2B) mean ERP waveforms (i.e., the sum of the identified component waveforms) at each of the midline sites ranged between 0.98 (for Go at Fz, and NoGo at $\mathrm{Fz}$ and $\mathrm{Pz}$ ) and 0.99, and were all highly significant ( $p$ $<$.001), confirming a good approximation to the raw data. In temporal order, based on their latency, scalp topography, and similarity to components in previous studies (using epochs extending to 750 ms only: Barry and De Blasio, 2013, 2015; Barry et al., 2014a,b,c), these components were identified as P1, N1-1, PN, a P2/N2b complex, N2c, P3, SW, and LP. These were followed by two components tentatively labelled as SW2 and LP2. Although later than components included in the schema (based on shorter ERP epochs) and not investigated further, these may be important in subsequent processing and are mentioned for completeness. Figure 3 (top) shows the scaled factor loadings for each identified component, together with their factor order, \% variance carried, peak latency, and peak amplitude distributions (averaged across Go/NoGo).

Fig. 3 about here

In the older adults, the first 8 PCA components were tentatively identifiable and together explained $90.2 \%$ of the variance; no further components carried more than $0.7 \%$ variance. Correlations between the raw (Figure 2C) and reconstituted (Figure 2D) mean 
waveforms at each of the midline sites were all 0.98 , and highly significant $(p<.001)$, again confirming a good approximation to the raw data. In temporal order, based on their latency, scalp topography, and similarity to components in this and previous PCA investigations in younger adults (Barry and De Blasio, 2013, 2015; Barry et al., 2014a,b,c), the components were identified as P1, N1-1, PN, P2/N2b, P3a, P3b, SW, and LP. Figure 3 (bottom) shows the peak amplitude topographies (across Go/NoGo), factor order, \% variance carried, latency, and scaled factor loadings.

The topographies of these components, and their demonstration of differences in response to Go vs. NoGo stimuli, are examined for each group separately below. The corresponding statistics are presented in Table 2 and Table 3, respectively, and the separate Go/NoGo topographies are illustrated in Figure 4. Note that two colour scales are used in Figure 4 to better demonstrate the component topographies in select components; these are indicated via the presence or absence of a box enclosing the Go/NoGo headmaps and scale. As the statistical tables can appear rather complex, the topographic statistics for the first analysis (young P1) are presented in-text in addition to the tables to aid the reader's understanding.

Fig. 4, Table 2, Table 3 about here

\subsection{Young component topography and Go/NoGo effects}

Across conditions the young adult P1 was frontal $\left(\mathrm{F}>\mathrm{P}: \mathrm{F}=14.52, p<.001, \eta_{\mathrm{p}}{ }^{2}=\right.$ $.43)$ and hemispheric $\left(\mathrm{M}<\mathrm{L} / \mathrm{R}: F=4.90, p=.039, \eta_{\mathrm{p}}{ }^{2}=.21\right)$, somewhat more so on the left (L $>\mathrm{R}: F=3.10, p=.095, \eta_{\mathrm{p}}{ }^{2}=.14$ ), as indicated in Table 2 (left). Figure 3 (top) and statistical outcomes for topography in Table 2 (left) show that the frontal dominance was larger in the midline $\left(\mathrm{F}>\mathrm{P} \times \mathrm{M}>\mathrm{L} / \mathrm{R}: F=12.38, p=.002, \eta_{\mathrm{p}}{ }^{2}=.39\right)$, and a central enhancement was larger in the hemispheres $\left(\mathrm{C}>\mathrm{F} / \mathrm{P} \times \mathrm{M}<\mathrm{L} / \mathrm{R}: F=8.32, p=.010, \eta_{\mathrm{p}}{ }^{2}=.30\right)$, particularly on the left $\left(\mathrm{C}>\mathrm{F} / \mathrm{P} \times \mathrm{L}>\mathrm{R}: F=6.32, p=.021, \eta_{\mathrm{p}}{ }^{2}=.25\right)$. Overall, $\mathrm{P} 1$ appeared somewhat larger for NoGo than Go (compare P1 headmaps in Figure 4, top), but no effects approached significance (Table 3). 
Over conditions, N1-1 was frontocentral and midline, with a frontal-right

enhancement; see Table 2 (left) and Figure 3 (top). N1-1 to Go was enhanced centrally, in the midline, and somewhat at the vertex; see statistical outcomes for condition effects in Table 3 (left).

Over Go and NoGo, the defining temporal negativity of the PN (Näätänen and Picton, 1987) was apparent as a central dominance that was enhanced in the hemispheres. Negativity was also greater frontally, and in the right hemisphere; see Table 2 (left) and Figure 3 (top). The hemispheric and central dominance in the hemispheres defining PN were enhanced in Go. Despite this, negativity in frontal, central, and frontal midline regions was enhanced in NoGo, leading to an overall greater negativity in NoGo than Go; this can be seen in Figure 4 (top) and Table 3 (left) - note that the joint underlining of the effect and statistics indicates an effect reversal (i.e., here $\underline{\text { Go }>\text { NoGo }} \equiv$ Go $<$ NoGo).

Across conditions, the young P2/N2b had a central positivity with negativity in frontal/parietal regions, with more negativity in the right than left hemisphere. The central positivity was somewhat greater in both the midline and in the left hemisphere; see Table 2 (left) and Figure 3 (top). In Go, positivity was enhanced in the midline and vertex, as was the overall response, supporting identification of the Go component as P2; see Table 3 (left). In NoGo, there was a fronto-parietal negativity that was somewhat greater frontally (c.f. parietally), and significantly so in the left and midline regions, suggesting that this component can be identified as an anterior NoGo N2b. The N2b negativity was reduced in the left hemisphere, somewhat more so centrally, due to the relative positivity in this region. Figure 4 (top) clearly shows the topographic separation of this component into the Go P2 and NoGo N2b.

Over conditions, Table 2 (left) shows that the negativity of N2c was enhanced in hemispheric regions, particularly on the right; the right hemispheric elevation was greater centrally as seen in Figure 3 (top). There was also a central-midline reduction. N2c negativity 
was enhanced centrally in Go as reported in Table 3 (left), and somewhat so in the parietal left; the latter effect is difficult to see in Figure 4 (top), even with the use of the more sensitive scale. NoGo N2c was enhanced in the frontal midline, and reduced somewhat in the central left.

Across Go and NoGo, the young P3 was centroparietal and midline dominant, as seen in Figure 3 (top) and reported in Table 2 (left). The central enhancement was larger in the midline and right hemisphere. P3 was parietal for Go and central for NoGo, as demonstrated in Figure 4 (top) and Table 3 (left). Go P3b was enhanced on the right, particularly centrally, and its parietal dominance was enhanced in the midline and left hemisphere. NoGo P3a was larger in the midline, and at the vertex, leading to an overall larger P3 to NoGo than Go.

Over conditions, the SW was centroparietally positive and frontally negative, with reduced positivity in the midline; see Figure 3 (top) and Table 2 (left). Also in the midline, the frontal negativity/parietal positivity was enhanced, and the central positivity was reduced. Figure 4 shows that in Go, the young SW was more positive centrally and parietally, and the NoGo SW was more negative frontally; see Table 3 (left) for statistics. The positive Go SW was enhanced in the midline and somewhat so in the left hemisphere, and both were significantly larger in the parietal region. Overall, the positive SW was greater for Go than NoGo.

Figure 3 (top) shows that the LP was larger centrally, in the right hemisphere, and was somewhat enhanced in the central hemispheres, and significantly enhanced in the central-right area, and in the frontal hemispheric regions; also see Table 2 (left). NoGo LP was enhanced parietally. Go LP was enhanced in the right hemisphere centrally due to the negativity in the left hemisphere as seen in Figure 4 (top) and Table 3 (left). Overall, the LP was positive across the assessed sites in NoGo, and was larger than in Go.

\subsection{Older component topography and Go/NoGo effects}

Across Go and NoGo the older adult P1 was central, particularly on the left, and a parietal enhancement was somewhat larger on the right; see Figure 3 (bottom) and statistical 
outcomes for topography in Table 2 (right). The central-left P1 enhancement was larger for Go than NoGo, as was activity in the left hemisphere; compare Go/NoGo headmaps in Figure 4 (bottom), and see statistical outcomes involving condition in Table 3 (right). There was no overall Go/NoGo difference.

Over conditions, the older adult N1-1 was frontocentral and midline; the frontal elevation was greater in the hemispheres, and the central elevation was larger in the left hemisphere (see Table 2, right). N1-1 to Go was enhanced in the left hemisphere, and particularly in the central left region, but there was no main effect of condition as reported in Table 3 (right).

As reported in Table 2 (right), the defining temporal PN negativity (Näätänen and Picton, 1987) was apparent across Go and NoGo as a central dominance that was enhanced in the hemispheres in the older adults. Furthermore, the PN was greater hemispherically, and in the right hemisphere, but was reduced in the parietal midline. In Go, the hemispheric PN dominance was significantly enhanced, with an enhancement of the defining central hemispheric negativity. Despite this, frontal negativity was enhanced in NoGo, particularly in the midline region, leading to an overall greater negativity in NoGo than Go; see Table 3 (right).

Across conditions, the older adult P2/N2b had a central positivity that approached significance. The parietal positivity was greater in the hemispheres than midline; see Table 2 (right). In Go, relative positive enhancements were found in the midline, particularly in the frontal midline, and in the vertex region (see Table 3, right), compatible with its identification as P2. A frontal negativity was greater in NoGo, compatible with the anterior N2b. There was no main Go/NoGo effect.

The older adult P3a was frontal (note the underlining in Table 2 indicating an effect reversal) and midline dominant over conditions, and the central positivity was somewhat greater in the right hemisphere; see Figure 3 (bottom). NoGo P3a was larger frontocentrally, and in the 
midline and left hemisphere; the NoGo central enhancement was larger on the left, and largest in the midline. These differences led to an overall larger P3a to NoGo than Go as reported in Table 3 (right).

Across conditions, the older adult P3b was relatively parietal, but no topographic contrasts approached significance and hence this component is excluded from Table 2. Table 3 (right) indicates that P3b was larger parietally for Go than NoGo, particularly in the midline and left hemisphere, but the overall P3b amplitude did not differ significantly between Go and NoGo.

Over Go and NoGo, the older adult SW was more positive centroparietally, and midline dominant, with no indication of the classic frontal negativity (see Table 2, right). The parietal positivity was enhanced in the midline. As reported in Table 3 (right), the older SW was somewhat more positive centrally for Go than NoGo, while more positive parietally, particularly on the right, for NoGo than Go. Overall, the older adult SW did not differ significantly in mean amplitude between Go and NoGo.

The LP was small in the older adults, but positive in all regions, as shown in Figure 3. It was larger in the midline and right hemisphere as reported in Table 2 (right). The NoGo LP was enhanced parietally, particularly in the midline (see Table 3). Overall, the LP did not differ significantly between Go and NoGo.

\subsection{Comparison of Young vs. Older group components}

Similarities and differences between the young and older adult components are indicated in their 1. latencies, 2. time course (i.e., factor loading onset/offset and amplitude in Figure 3), and 3. topographic distribution (in Figures 3 and 4).

First, Figure 5 shows a scatterplot of the older adult mean latencies plotted against the corresponding component latencies in the young; note that the young N2c component is omitted as there was no older adult equivalent, and the older P3a and P3b (labelled in Figure 5) are each plotted against the young P3. It is evident that the latencies are generally longer in the older 
group, and increasingly so from P1 to the LP. A line of best fit (forced through the origin for simplicity) had a slope of 1.2564 with $r=.99(p<.001)$, indicating that the component latencies in the older adults are approximately $25.6 \%$ longer than those in the young.

Fig. 5 about here

Second, we used a cubic spline interpolation to resample the Young group loadings at 2/1.2564 ms to adjust for their systematic increase in latency, and compared Older and adjusted Young group unscaled loadings for the post-stimulus period. These values are shown as the "adjusted $r_{c}$ " in the centre of Figure 3. Using the common "rule-of-thumb" from Lorenzo-Seva and ten Berge (2006), it can be seen that the loading structure of the P1, N1-1, and P3/P3a components are similar (i.e., .85 $\leq r_{c} \leq .94$ ), while the young and older adult PN, SW and LP components can be considered equivalent (i.e., $r_{c}>$.95). The P2/N2b and P3/P3b components can be considered to differ (i.e., $r_{c}<.84$ ); this can be attributed to the relatively-small component loadings in the older group (i.e., compare factor loadings of P2/N2b in Figure 3: Young 5 vs. Older 8).

Third, comparisons of topographies are summarised in the $r(36)$ values in Figure 4. These data show that, across Go and NoGo, significant topographic correlations occurred between the young and older adults (in descending order of magnitude) for N1-1, PN, P3/P3b (all $p<.001), \mathrm{P} 2 / \mathrm{N} 2 \mathrm{~b}$ and LP (both $p=.003)$, SW $(p=.016)$, and P3/P3a $(p=.031)$, but failed to reach significance for $\mathrm{P} 1(p=.090)$. These results provide data independent of the adjusted Congruence Coefficients noted above.

\section{Discussion}

\subsection{Behavioural and ERP Morphology Changes with Age}

The older adults showed little decrement in performance from the young group; this was somewhat unexpected. There was a slight increase in RT in older participants, and they had significantly greater within-subject RT variability than the young adults. There was also a 
slight increase in Go omission errors, but a slight decrease for response execution errors (fast RTs and commission errors to NoGo). However, these and the remaining performance indicator (Slow RTs) failed to differ significantly from that of the young participants, demonstrating the capacity of the older adults to perform well in this simple task. Indeed, there is an overall suggestion that the older participants were slightly slower and more careful/less impulsive than the young participants, but with less consistency in their trial-to-trial RTs. The latter finding is often considered to indicate neurodegeneration in older adults (see review by MacDonald et al., 2009).

In contrast to this behavioural similarity, the older group showed markedly different ERP morphology, as evident in Figure 2. In particular, P3 was more prolonged in latency, somewhat less differentiated by Go and NoGo, and both P3a and P3b responses appear smaller, more frontal, and more equipotential in the older group. These general P3 effects are broadly compatible with the early findings of Ford et al. (1979), Pfefferbaum et al. (1980), Friedman et al. (1997), and Polich (1997). The absence of the classic frontally-negative SW is also notable, and mimics that reported in Pfefferbaum et al. (1980).

\subsection{Confirmation of the Young Processing Schema}

In the young group, the PCA decomposition into ten components gave a good fit to the raw ERP data, and the first eight of these in latency order generally matched topographic and Go/NoGo expectations from our processing schema for this paradigm (Figure 1 and Barry and De Blasio, 2013, 2015). The young P1 was comparable for Go and NoGo, and N1-1 was topographically larger for Go. These reflect early sensory processing and the emerging of sensory differentiation between the Go and NoGo stimuli. The following PN was topographically better defined for Go, compatible with "the processing of an attended auditory stimulus” (Näätänen and Picton, 1987, P. 412). Marking the beginning of separate processing was the differentiation of the vertex P2 to Go and frontal N2b to NoGo. The Go processing chain leading to the button press was subsequently marked by a central N2c, parietal P3b, and 
classic SW. The distinct processing chain for NoGo that emerged in the frontal N2b continued in the vertex P3a, and diffuse LP. This confirmation of the response patterning in a new sample of young adults indicates the stability of this processing schema and encourages its further use and development. Moreover, the two novel components (SW2, LP2), tentatively identified but not assessed here, indicate the merit in extending the epoch beyond $750 \mathrm{~ms}$ (as previously assessed; Barry and De Blasio, 2013, 2015; Barry et al., 2014a,b,c). This schema provides a yardstick to assess the Older group's ERP markers of perceptual and cognitive processing in this paradigm, and may clarify function and dysfunction in our Older group.

\subsection{Similar Processing Schema in Older Participants}

The Older group's PCA extracted eight components for a comparably-good fit with the raw ERP data. Identified as P1, N1-1, PN, P2/N2b, P3a, P3b, SW and LP, these generally matched the young components. However, the Older group showed little evidence of the Young Go-dominant N2c, and the Young P3a/P3b complex was separated in the Older group.

The older P1 and N1-1 were topographically enhanced for Go, reflecting early sensory processing and the emerging of sensory differentiation between the Go and NoGo stimuli in the older participants, similar to that in the young. The following PN was again better defined for Go, marking the beginning of the selective attentional focus on the Go stimulus. This was followed by an enhanced Go P2 as in the young, but it was more frontal than the young vertexmaximum P2. Following this was a weaker P3b similar in topography to the young parietal P3b, and a SW that lacked the classic frontal negativity/parietal positivity found in the young; see Figure 4. The processing chain for NoGo emerged in a weak frontal N2b, a frontocentral P3a that was significantly larger than the Go P3a (as in the Young group), a small and parietally positive SW, and a small parietally-enhanced LP. Essentially, apart from a “missing” N2c (meaning that this component carried less than $0.7 \%$ of the variance), these results indicate that Older processing stages in the Go/NoGo task are similar to those identified in Young adults.

\subsection{Age differences in ERP Components}


Across all the extracted components, the Older group showed systematic ERP component latency increases of some $26 \%$ compared with the corresponding young component latencies, consistent with Goodin et al.'s (1978) finding based on ERP peak measures. After adjusting for this latency shift, the adjusted Congruence Coefficients supported the broad match between the young and older adult components. That is, the PCAs decomposed the young and older adult ERPs into components that reflected corresponding stages of sequential processing with similar timing characteristics (peak latency, rise/fall times) and relative amplitudes, although with a systematic increase in latency of $\sim 26 \%$ in the Older group. For future research it is important to note that this latency increase means that a continuous age distribution would confound the extraction of common components using a temporal PCA.

Despite this similarity, differences between the young and older components in the Go/NoGo processing chains were reflected in the topographic correlations over sites and condition, and these will be considered in temporal order. The young P1 was frontal, while the older P1 was central and topographically enhanced for Go. There was no correlation of topography across conditions, suggesting substantially-different brain generators of this component in the two groups. This needs confirmation in future PCA studies in this paradigm, and might benefit from source analysis such as exact low-resolution electromagnetic tomography (eLORETA; Pascual-Marqui et al., 2011). N1-1 and PN showed broadly similar topographies and Go/NoGo effects in the two age groups, and this was reflected in their high topographic correlations across site and condition. Apart from the P1 differences in topography, this suggests comparable sensory processing in young and older participants up to the beginning of the separate processing chains evidenced in the young group.

In relation to these separate processing chains, the young Go P2/NoGo N2b is substantially paralleled by the older Go P2/NoGo N2b, although the P2 is more frontal and both sub-components are weaker in the Older group. Subsequently, the young N2c failed to appear in the older PCA. The young composite P3 (with Go P3b and NoGo P3a) was replaced by two 
separate P3s in the older adults. The older P3a loading structure and topography was similar to that of the young P3, despite the NoGo P3a being dominant at the vertex in the young group, but frontocentral in the older group. The subsequent older P3b loading structure differed from that of the young P3, primarily attributable to the relatively small older P3b, but both showed substantial topographical correlation over conditions, compatible with recent PCA results from Alperin et al. (2014). The subsequent young and older adult SW and LP had virtually identical loading structures, and showed significant but moderate topographical similarity over site and conditions. For instance, the older SW lacked the frontal negativity of the classic SW and the Go/NoGo effects were weak and few. Weak Go/NoGo effects continued in the LP, but it did show a significant parietal elevation in NoGo, a shadow of the global enhancement in the Young group.

\subsection{Implications}

These results suggest that the separate Go/NoGo processing chains apparent in the young participants are not as distinct in the Older group, reflecting the apparent increase in similarity of the Go/NoGo ERP morphologies apparent in Figure 2. Given the similarity in behavioural performance outcomes between the groups, together with the more dispersed nature of the associated ERP component topographies evident in Figure 4, this comparable investment of resources in Go and NoGo specific processing by the Older group likely reflects a wider utilisation of less specialist processing areas. This could underlie the reduced Go N2c and P3b, and increased within-subject RT variability, noted in the Older group. Moreover, the enhanced and topographically-different P1 in the Older group might suggest enhanced prestimulus focus on the task, which would be compatible with the investment of greater effort. These interpretations are consistent with the typical view that older adults employ compensatory mechanisms in order to perform satisfactorily (e.g., Friedman et al., 1997; Hong et al., 2014; Hsieh and Fang, 2012; Staub et al., 2014; Vallesi, 2011).

However, an alternative interpretation is that the older adults are more efficient in 
utilising the resources involved in Go and NoGo processing. This suggestion is compatible with the general reduction in the negativity of the older components apparent in Figure 4, perhaps reflecting less cortical activation, and the weaker N2b and apparent absence of (or at least weaker) N2c. For instance, children show enhanced N2 frontal negativity in this paradigm (Barry and De Blasio, 2015; Barry et al., 2014a), and we have recently found that greater child NoGo N2b amplitudes were related to improved NoGo performance, independent of age (Barry and De Blasio, 2015). Response inhibition therefore appears to be an important NoGo processing step in 8-12 year olds, even in the absence of a pre-potent Go response in this equiprobable paradigm (Barry and De Blasio, 2015). In the present study, a young adult NoGo $\mathrm{N} 2 \mathrm{~b}$ is apparent, suggesting that this population may also be utilising some response inhibition in the NoGo processing chain, while the older adults show a reduced indication of this process.

A third, but perhaps related explanation, is that the young and older adults adopted different strategies towards the task. In the present study, the young adult participants occasionally enquired about their speed, while the older adults often enquired about their accuracy, despite both groups receiving the same set of instructions equally emphasising both speed and accuracy. This may reflect a difference in the relative perceived importance of the task-specific processing between the groups (i.e., more personal importance may be placed by the young on Go response speed, and by the older adults on Go and NoGo accuracy). This is compatible with the somewhat greater occurrence of fast RT errors, suggestive of impulsive responding, in the young participants. These alternative interpretations cannot be separated here, but they suggest intriguing possibilities that should be explored in future studies of normal ageing.

Detailed understanding of the indicators of normal functioning in the elderly would provide a useful basis for ERP explorations in those with mild cognitive impairment or dementia. The simple equiprobable auditory Go/NoGo paradigm is easy to implement and has been successfully completed by healthy individuals from age 8 (Barry and De Blasio, 2015; 
Barry et al., 2014a) to 75 (the present study), and we see no reason to suggest that there are barriers to extending this range further. The PCA approach used here yielded a data-driven decomposition of the ERP into its underlying components and sub-components, and helped clarify cognitive processing in healthy ageing. The confirmation of our sequential processing schema (Barry and De Blasio, 2013, 2015) here in young adults, and its extension to healthy older adults, provides a cognitive framework to understand the neuropsychological processing involved in this task. Together, this paradigm and schema appear to offer a valuable toolkit for assessing processing deficits in these and other populations.

\section{Acknowledgement}

We thank Prof. Craig Gonsalvez for his contributions to this project. We also thank The Illawarra Retirement Trust (IRT) and the management of IRT Links Seaside Resort for their kind assistance in providing facilities and encouraging resident participation in this project.

\section{Conflicts of interest}

The authors have no conflicts of interest. 


\section{References}

Alperin, B.R., Mott, K.K., Rentz, D.M., Holcomb, P.J., Daffner, K.R. (2014). Investigating the age-related "anterior shift" in the scalp distribution of the P3b component using principal component analysis. Psychophysiology, 51, 620-633. doi: 10.1111/psyp.12206

Anguera, J.A., Gazzaley, A. (2011). Dissociation of motor and sensory inhibition processes in normal aging. Clin. Neurophysiol., 123, 730-740. doi: 10.1016/j.clinph.2011.08.024

Barry, R.J., De Blasio, F.M. (2012). EEG-ERP phase dynamics of children in the auditory Go/NoGo task. Int. J. Psychophysiol., 86, 251-261. doi: 10.1016/j.ijpsycho.2012.10.001

Barry, R.J., De Blasio, F.M. (2013). Sequential processing in the equiprobable auditory Go/NoGo task: A temporal PCA study. Int. J. Psychophysiol., 89, 123-127. doi: 10.1016/j.ijpsycho.2013.06.012

Barry, R.J., De Blasio, F.M. (2015). Performance and ERP components in the equiprobable Go/NoGo task: Inhibition in children. Psychophysiology, 52, 1228-1237. doi: 10.1111/psyp.12447

Barry, R.J., De Blasio, F.M., Borchard, J.P. (2014a). Sequential processing in the equiprobable auditory Go/NoGo task: Children vs. adults. Clin. Neurophysiol., 125, 1995-2006. doi: 10.1016/j.clinph.2014.02.018

Barry, R.J., De Blasio, F.M., Cave, A.E. (2014b). Caffeine effects on ERP components and performance in an equiprobable auditory Go/NoGo task. J. Caffeine Res., 4, 83-92. doi: 10.1089/jcr.2014.0011

Barry, R.J., De Blasio, F.M., De Pascalis, V., Karamacoska, D. (2014c). Preferred EEG brain states at stimulus onset in a fixed interstimulus interval equiprobable auditory Go/NoGo task: A definitive study. Int. J. Psychophysiol., 94, 42-58. doi:

10.1016/j.ijpsycho.2014.07.005 
Barry, R.J., De Blasio, F.M., Rushby, J.A., Clarke, A.R. (2010). Brain dynamics in the auditory Go/NoGo task as a function of EEG frequency. Int. J. Psychophysiol., 78, 115-128. doi: 10.1016/j.ijpsycho.2010.06.357

Barry, R.J., Rushby, J.A. (2006). An orienting reflex perspective on anteriorisation of the P3 of the event-related potential. Exp. Brain Res., 173, 539-545. doi:10.1007/s00221-006-0590-8

Beck, E.C., Swanson, C., Dustman, R.E. (1980). Long latency components of the visually evoked potential in man: Effects of aging. Exp. Aging Res., 6, 523-545. doi: $10.1080 / 03610738008258385$

Čeponienè, R., Westerfield, M., Torki, M., Townsend, J. (2008). Modality-specificity of sensory aging in vision and audition: Evidence from event-related potentials. Brain Res., 1215, 5368. doi: 10.1016/j.brainres.2008.02.010

Croft, R.J., Barry, R.J. (2000). EOG correction of blinks with saccade coefficients: A test and revision of the aligned-artefact average solution. Clin. Neurophysiol., 111, 444-451. doi: 10.1016/S1388-2457(99)00296-5

Crowley, K.E., Colrain, I.M. (2004). A review of the evidence for P2 being an independent component process: Age, sleep and modality. Clin. Neurophysiol., 115, 732-744. doi: 10.1016/j.clinph.2003.11.021

De Blasio, F.M., Barry, R.J. (2013a). Prestimulus delta and theta determinants of ERP responses in the Go/NoGo task. Int. J. Psychophysiol., 87, 279-288. doi: 10.1016/j.ijpsycho.2012.09.016

De Blasio, F.M., Barry, R.J. (2013b). Prestimulus alpha and beta determinants of ERP responses in the Go/NoGo task. Int. J. Psychophysiol., 89, 9-17. doi:10.1016/j.ijpsycho.2013.04.018

Dien, J. (2010). The ERP, PCA toolkit: An open source program for advanced statistical analysis pf event-related potential data. J. Neurosci. Meth., 187, 138-145. doi:

10.1016/j.jneumeth.2009.12.009 
Dien, J. (2012). Applying principal components analysis to event-related potentials: A tutorial.

Devel. Neuropsychol., 37, 497-517, doi: 10.1080/87565641.2012.697503

Driscoll, I., Davatzikos, C., An, Y., Wu, X., Shen, D., Kraut, M., Resnick, S.M. (2009). Longitudinal pattern of regional brain volume change differentiates normal aging from MCI. Neurology, 72, 1906-1913. doi: 10.1212/WNL.0b013e3181a82634

Duncan-Johnson, C.C., Donchin, E. (1977). On quantifying surprise: The variation of eventrelated potentials with subjective probability. Psychophysiology, 14, 456-467. doi: 10.1111/j.1469-8986.1977.tb01312.x

Falkenstein, M., Yordanova, J., Kolev, V. (2006). Effects of aging on slowing of motor-response generation. Int. J. Psychophysiol., 59, 22-29. doi: 10.1016/j.ijpsycho.2005.08.004

Folstein, J.R., van Petten, C. (2008). Influence of cognitive control and mismatch on the N2 component of the ERP: A review. Psychophysiology, 45, 152-170. doi: 10.1111/j.14698986.2007.00602.x

Ford, J.M., Hink, R.F., Hopkins III, W.F., Roth, W.T., Pfefferbaum, A., Kopell, B.S. (1979). Age effects on event-related potentials in a selective attention task. Gerontology, 34, 388395. doi: 10.1093/geronj/34.3.388

Fozard, J.L., Vercruyssen, M., Reynolds, S.L., Hancock, P.A., Quilter, R.E. (1994). Age differences and changes in reaction time: The Baltimore longitudinal study of aging. $J$. Gerontol., 49, 179-189. doi: 10.1093/geronj/49.4.P179

Friedman, D., Kazmerski, V., Fabiani, M. (1997). An overview of age-related changes in the scalp distribution of P3b. Electroen. Clin. Neuro., 104, 498-513. doi: 10.1016/S01685597(97)00036-1

Goodin, D.S., Squires, K.C., Henderson, B.H., Starr, A. (1978). Age-related variations in evoked potentials to auditory stimuli in normal human subjects. Electroen. Clin. Neuro., 44, 447458. doi: 10.1016/0013-4694(78)90029-9 
Grassi, M., Borella, E. (2013). The role of auditory abilities in basic mechanisms of cognition in older adults. Front. Aging Neurosci., 5, 59. doi: 10.3389/fnagi.2013.00059

Ho, M.-C., Chou, C.-Y., Huang, C.-F., Lin, Y.-T., Shih, C.-S., Han, S.-Y., et al. (2012). Agerelated changes of task-specific brain activity in normal aging. Neurosci. Lett., 507, 7883. doi: 10.1016/j.neulet.2011.11.057

Hong, X., Sun, J., Bengson, J.J., Tong, S. (2014). Age-related spatiotemporal reorganization during response inhibition. Int. J. Psychophysiol., 93, 371-380. doi: 10.1016/j.ijpsycho.2014.05.013

Hsieh, S., Fang, W. (2012). Elderly adults through compensatory responses can be just as capable as young adults in inhibiting the flanker influence. Biol. Psychol., 90, 113-126. doi: 10.1016/j.biopsycho.2012.03.006

Huster, R.J., Enriquez-Geppert, S., Lavallee, C.F., Falkenstein, M., Herrmann, C.S. (2013). Electroencephalography of response inhibition tasks: Functional networks and cognitive contributions. Int. J. Psychophysiol., 87, 217-233. doi: 10.1016/j.ijpsycho.2012.08.001

Johnson, Jr R. (1986). A triarchic model of P300 amplitude. Psychophysiology, 23, 367-384. doi: 10.1111/j.1469-8986.1986.tb00649.x

Kayser, J., Tenke, C.E. (2003). Optimizing PCA methodology for ERP component identification and measurement: Theoretical rationale and empirical evaluation. Clin. Neurophysiol., 114, 2307-2325. doi: 10.1016/S1388-2457(03)00241-4

Lorenzo-Seva, U., ten Berge, J.M.F. (2006). Tucker's congruence coefficient as a meaningful index of factor similarity. Methodology (Gott), 2, 57-64. doi: 10.1027/1614-1881.2.2.57

MacDonald, S.W.S., Li, S.-C., Bäckman, L. (2009). Neural underpinnings of within-person variability in cognitive functioning. Psychol. Aging, 24, 792-808. doi: 10.1037/a0017798

Marsh, G.R., Thompson, L.W. (1972). Age differences in evoked-potentials during an auditory discrimination task. Gerontologist, 12, 44. 
Näätänen, R., Picton, T. (1987). The N1 wave of the human electric and magnetic response to sound: A review and an analysis of the component structure. Psychophysiology, 24, 375425. doi: 10.1111/j.1469-8986.1987.tb00311.x

O'Brien, R.G., Kaiser, M.K. (1985). MANOVA method for analyzing repeated measures designs: An extensive primer. Psychol. Bull., 97, 316-333. doi: 10.1037/00332909.97.2.316

Pascual-Marqui, R.D., Lehmann, D., Koukkou, M., Kochi, K., Anderer, P., Saletu, B., et al. (2011). Assessing interactions in the brain with exact low-resolution electromagnetic tomography. Phil. T. Roy. Soc. A, 369, 3768-3784. doi: 10.1098/rsta.2011.0081

Pfefferbaum, A., Ford, J.M., Roth, W.T., Kopell, B.S. (1980). Age-related changes in auditory event-related potentials. Electroen. Clin. Neuro., 49, 266-276. doi: 10.1016/00134694(80)90221-7

Polich, J. (1997). EEG and ERP assessment of normal aging. Electroen. Clin. Neuro., 104, 244256. doi: 10.1016/S0168-5597(97)96139-6

Pritchard, W.S., Shappell, S.A., Brandt, M.E. (1991). Psychophysiology of N200/N400: A review and classification scheme. In J.R. Jennings \& P.K. Ackles (Eds.), Advances in psychophysiology: A research manual (Vol. 4, pp. 43-106). London: Jessica Kingsley Publishers Ltd.

Raz, N., Lindenberger, U., Rodrigue, K.M., Kennedy, K.M., Head, D., Williamson, A., et al. (2005). Regional brain changes in aging healthy adults: General trends, individual differences and modifiers. Cereb. Cortex, 15, 1676-1689. doi: 10.1093/cercor/bhi044

Staub, B., Doignon-Camus, N., Bacon, E., Bonnefond, A. (2014). The effects of aging on sustained attention ability: An ERP study. Psychol. Aging, 29, 684-695. doi: 10.1037/a0037067 
Storey, J., Rowland, J., Basic, D., Conforti, D. Dickson, H. (2004). The Rowland Universal Dementia Assessment Scale (RUDAS): A Multicultural Cognitive Assessment Scale. Int. Psychogeriatr., 16, 13-31. doi: 10.1017/S1041610204000043

Tabachnick, B.G., Fidell, L.S. (2013). Using multivariate statistics (6th ed.). England: Pearson Education Limited.

Tucker, L.R. (1951). A method for synthesis of factor analysis studies (Personnel Research Section Report No. 984). Washington, D.C., Department of the Army.

Vallesi, A. (2011). Targets and non-targets in the aging brain: A go/nogo event-related potential study. Neurosci. Lett., 487, 313-317. doi: 10.1016/j.neulet.2010.10.046

Yordanova, J., Kolev, V., Hohnsbein, J., Falkenstein, M. (2004). Sensorimotor slowing with ageing is mediated by a functional dysregulation of motor-generation processes: Evidence from high-resolution event-related potentials. Brain, 127, 351-362. doi: 10.1093/brain/awh042 


\section{Footnote}

${ }^{1}$ We follow Barry and Rushby (2006) in labelling the centroparietal Go P3 as P3b, and the frontocentral NoGo P3 as P3a. 


\section{Figure legends}

Figure 1. Illustration of the ERP peaks and PCA-derived components and sub-components in relation to the processing schema, based on young adult data from Barry and De Blasio (2013), with updated labelling from Barry and De Blasio (2015). Panel A: Go and NoGo ERPs at Cz; Panel B: unscaled factor loadings (P1 and N1-3 are dashed as they often carry little variance, and were not fully analysed in the original data set) and mean topographic headmaps; Panel C: the processing schema. Components in the later stages of sensory processing are enhanced to Go and mark the beginning of stimulus categorization as Go or NoGo; complete categorization is marked by the separation of the Go P2 and NoGo N2b, each marking the beginning of a separate processing chain. For Go, this leads to production and execution of the button-press response, P3b and SW; for NoGo, termination of processing is associated with the P3a and diffuse LP. This figure is presented in colour online.

Figure 2. Left: Grand mean ERPs at the midline sites for the Young (top) and Older (bottom) groups. Right: Corresponding reconstituted ERPs derived from the sum of the identified components.

Figure 3. Scaled factor loadings, factor information, and across-condition topographic headmaps for each identified component for the Young (top) and Older (bottom) groups (in colour on the web). The Congruence Coefficients $\left(r_{c}\right)$, adjusted for the systematic latency shift, are shown in the middle row. This figure is available in colour online.

Figure 4. Topographic headmaps for each considered component in each (Go/NoGo) condition, with data for the Young group above that for the Older group (in colour on the web). The green boxes contain the headmaps and the scale values used for the smaller components. The middle 
row shows the Pearson topography correlation (over the pair of headmaps) between the groups. This figure is available in colour online.

Figure 5. Latencies for the common components from the Older group plotted against those from the Young group. A dashed line of best fit forced though the origin is shown, indicating that the latencies are some $26 \%$ longer in the older than the young adults. The separate Older P3a and P3b components are each labelled and plotted against the single Young P3 , and the mean reaction time (RT) comparison is also indicated. 


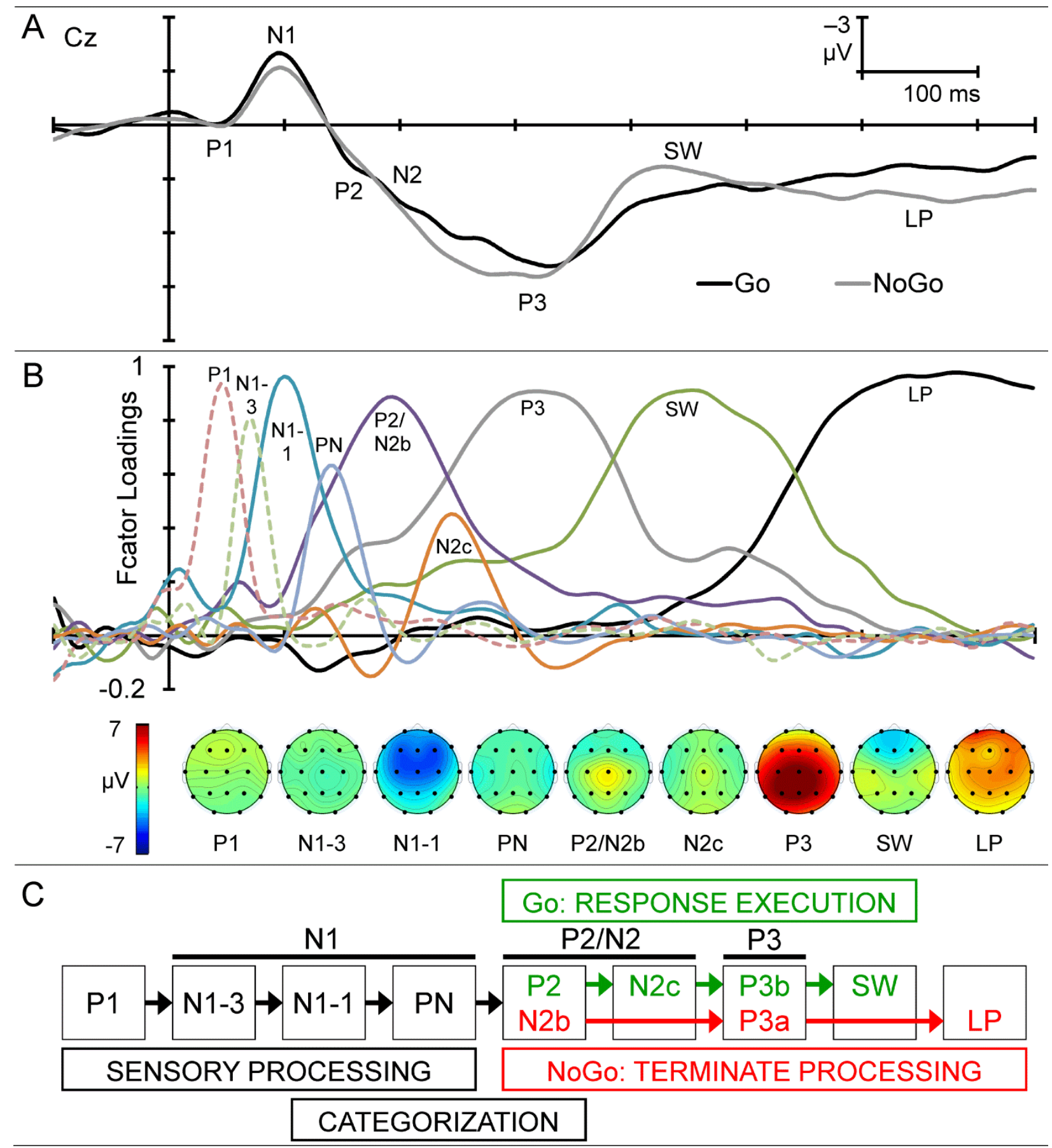




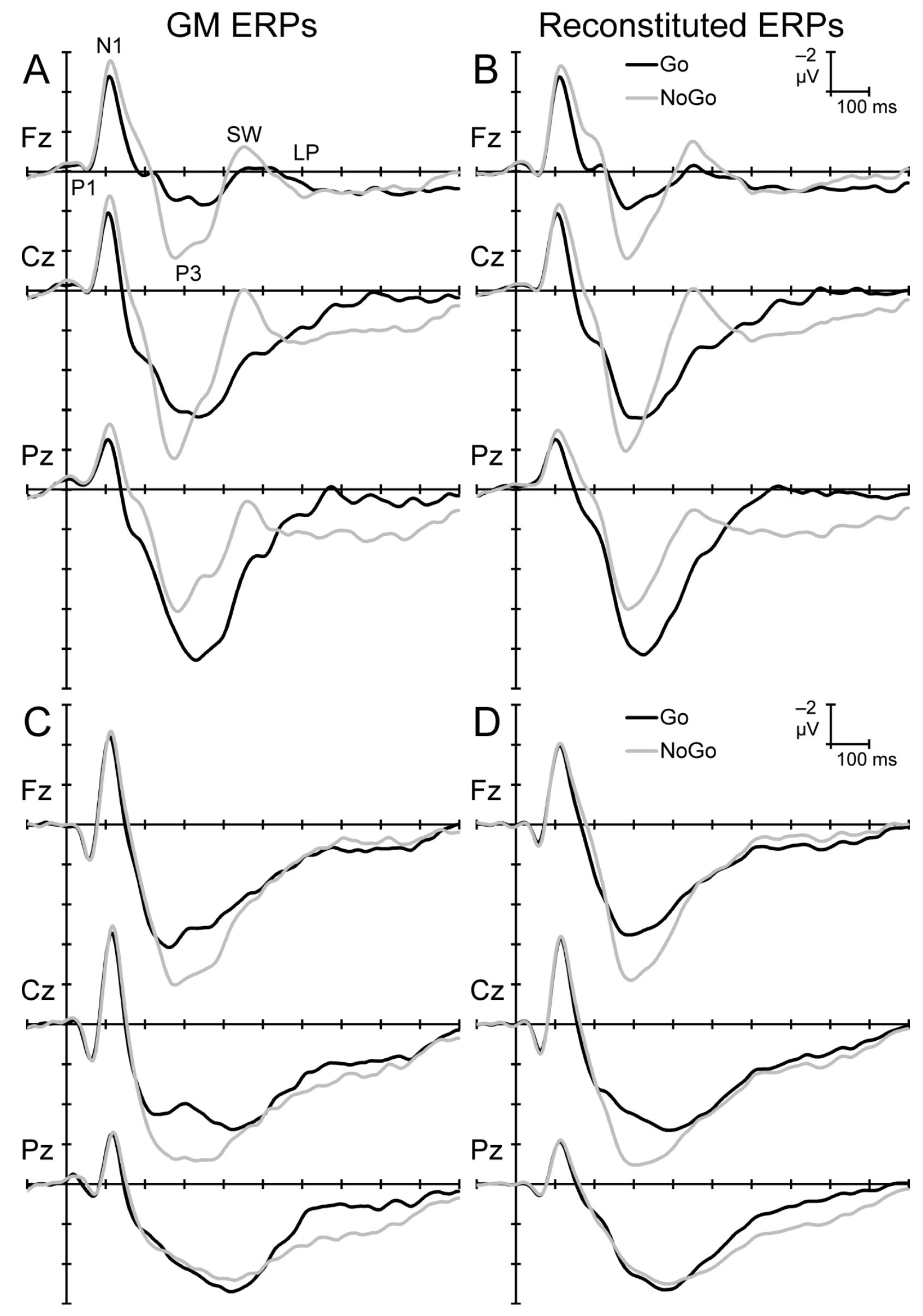




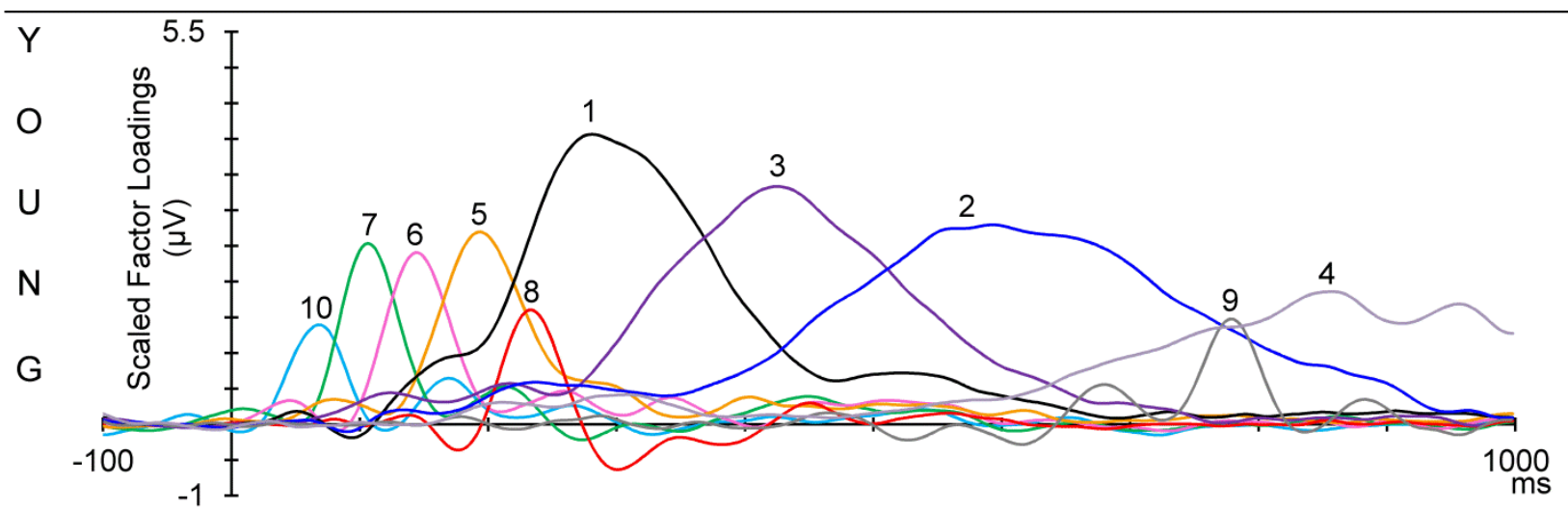

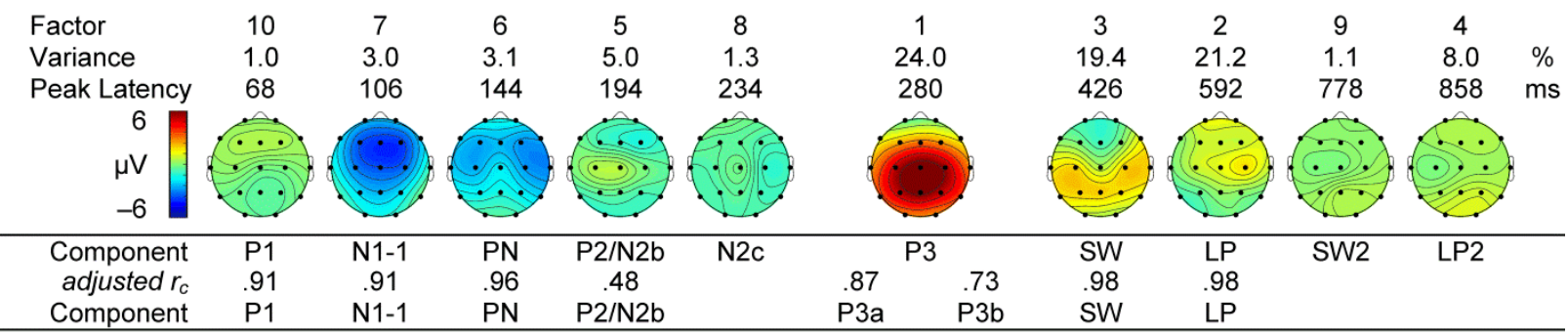

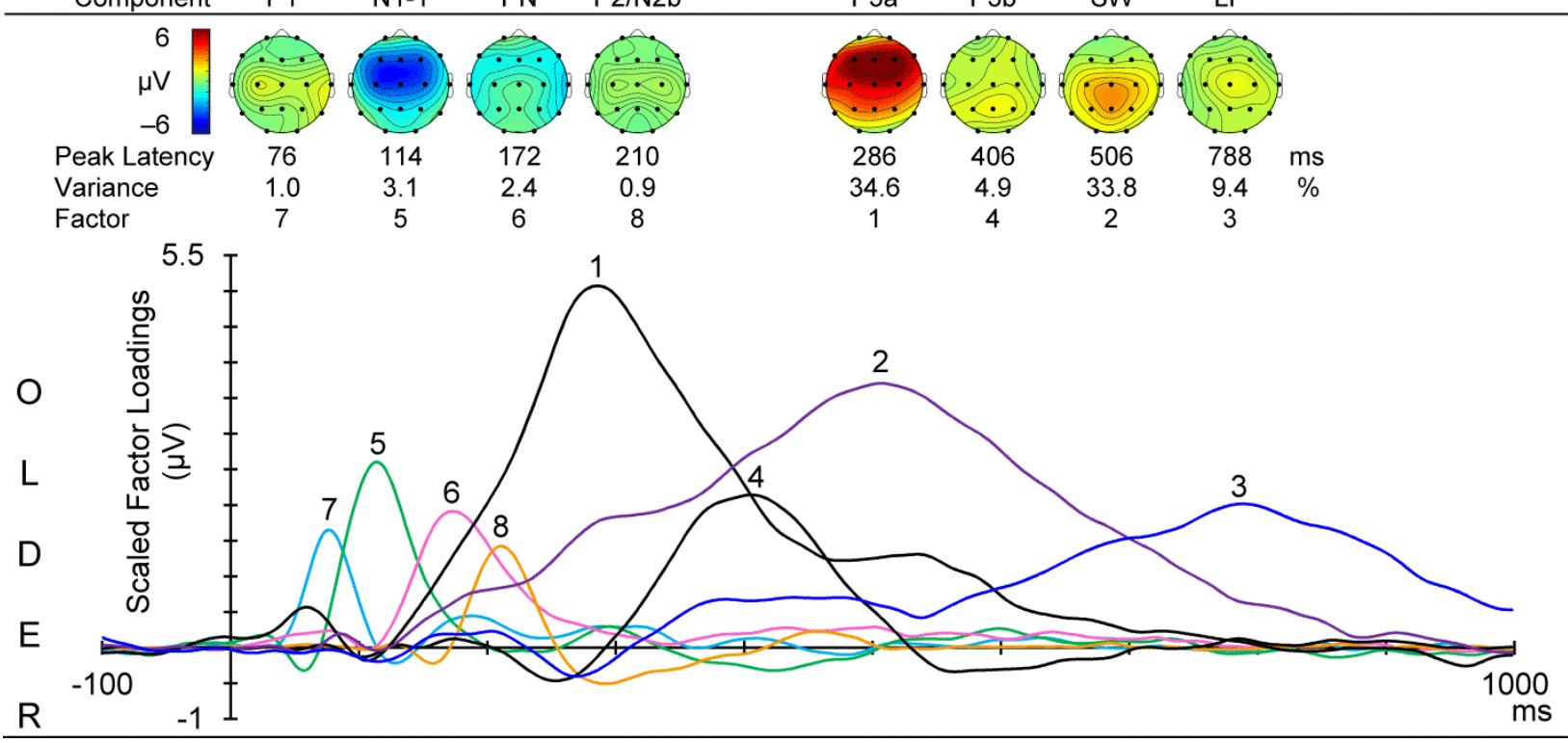




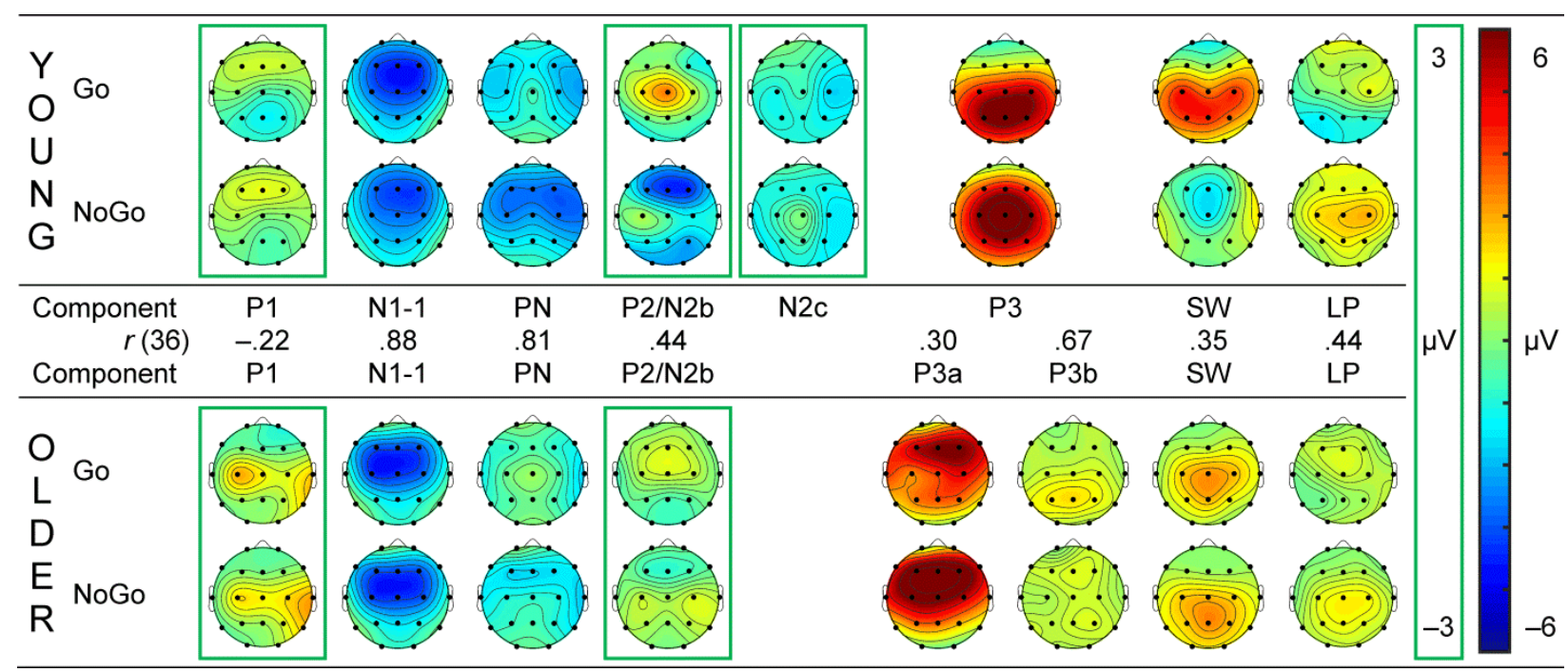




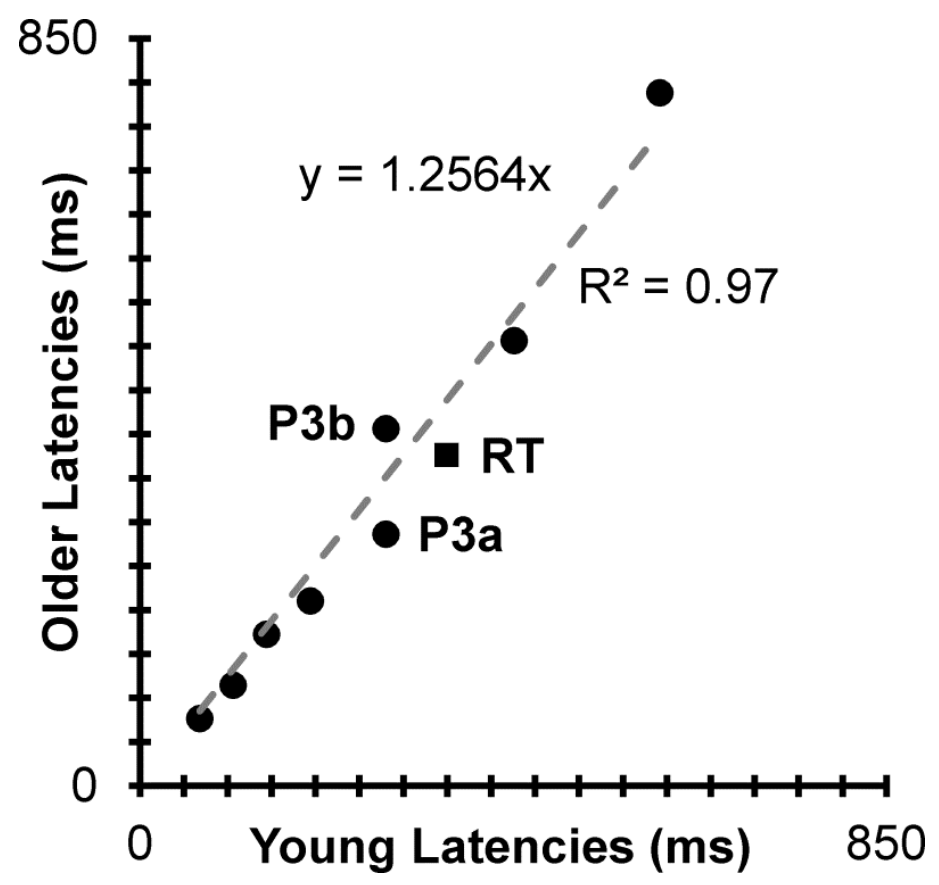


Table 1. Age and performance information (M $[S D])$ for each group, and statistical relationships between them.

\begin{tabular}{|c|c|c|c|c|c|c|c|c|c|}
\hline & \multirow[b]{2}{*}{ Age (years) } & \multicolumn{2}{|c|}{ Go RT (ms) } & \multicolumn{4}{|c|}{ Errors (\%) } & \multicolumn{2}{|c|}{$N$ Trials } \\
\hline & & Mean & ISD & Omissions & Fast RT & Slow RT & Commissions & Go & NoGo \\
\hline Young & $20.4(1.6)$ & 349.5 (58.9) & $66.0(15.7)$ & $0.6(0.7)$ & $0.5(0.6)$ & $3.8(0.8)$ & $3.8(4.5)$ & $279.0(7.2)$ & $282.0(14.6)$ \\
\hline Older & $68.2(4.5)$ & $376.0(58.3)$ & $83.0(25.2)$ & $1.5(3.5)$ & $0.2(0.6)$ & $4.0(1.0)$ & $2.7(2.0)$ & 274.9 (18.9) & 281.5 (24.5) \\
\hline$t(\operatorname{adj} . d f)$ & $-44.82(24.0)$ & $-1.43(38.0)$ & $-2.55(31.8)$ & $-1.13(20.7)$ & $1.47(38.0)$ & $-0.95(36.8)$ & $0.97(26.3)$ & $0.91(24.3)$ & $0.08(31.0)$ \\
\hline$p$ & $<.001$ & .080 & .008 & .135 & .075 & .175 & .169 & .187 & .469 \\
\hline
\end{tabular}

Note: ISD $=$ Intra-individual Standard Deviation; $t$ (adj. $d f)=1$-tailed $t$-test ( $d f$ adjusted to reflect unequal variances). 
Table 2. Topographical effects in the identified components in the young and older adult groups.

\begin{tabular}{|c|c|c|c|c|c|c|c|c|}
\hline \multirow[b]{2}{*}{ Young } & \multirow[b]{2}{*}{ Older } & \multirow[b]{2}{*}{ Effect } & \multicolumn{3}{|c|}{ Young } & \multicolumn{3}{|c|}{ Older } \\
\hline & & & $F$ & $p$ & $\eta_{p}{ }^{2}$ & $F$ & $p$ & $\eta_{p}^{2}$ \\
\hline \multirow[t]{8}{*}{$\mathrm{P} 1$} & $\mathrm{P} 1$ & $\mathrm{~F}>\mathrm{P}$ & 14.52 & $<.001$ & .43 & & & \\
\hline & & $\mathrm{C}>\mathrm{F} / \mathrm{P}$ & & & & 25.03 & $<.001$ & .57 \\
\hline & & $\mathrm{L}>\mathrm{R}$ & 3.10 & .095 & .14 & & & \\
\hline & & $\mathrm{M}<\mathrm{L} / \mathrm{R}$ & 4.90 & .039 & .21 & & & \\
\hline & & $\mathrm{F}>\mathrm{P} \times \mathrm{L}>\mathrm{R}$ & & & & 3.68 & .070 & .16 \\
\hline & & $\mathrm{F}>\mathrm{P} \times \mathrm{M}>\mathrm{L} / \mathrm{R}$ & 12.38 & .002 & .39 & & & \\
\hline & & $\mathrm{C}>\mathrm{F} / \mathrm{P} \times \mathrm{L}>\mathrm{R}$ & 6.32 & .021 & .25 & 12.15 & .002 & .39 \\
\hline & & $\mathrm{C}>\mathrm{F} / \mathrm{P} \times \mathrm{M}<\mathrm{L} / \mathrm{R}$ & 8.32 & .010 & .30 & & & \\
\hline \multirow[t]{6}{*}{ N1-1 } & N1-1 & $\mathrm{F}>\mathrm{P}$ & 28.10 & $<.001$ & .60 & 13.72 & .002 & .42 \\
\hline & & $\mathrm{C}>\mathrm{F} / \mathrm{P}$ & 4.38 & .050 & .19 & 35.32 & $<.001$ & .65 \\
\hline & & $\mathrm{M}>\mathrm{L} / \mathrm{R}$ & 16.36 & .001 & .46 & 9.50 & .006 & .33 \\
\hline & & $\mathrm{F}>\mathrm{P} \times \mathrm{L}<\mathrm{R}$ & 5.22 & .034 & .22 & & & \\
\hline & & $\mathrm{F}>\mathrm{P} \times \mathrm{M}<\mathrm{L} / \mathrm{R}$ & & & & 25.98 & $<.001$ & .58 \\
\hline & & $\mathrm{C}>\mathrm{F} / \mathrm{P} \times \mathrm{L}>\mathrm{R}$ & & & & 15.94 & .001 & .46 \\
\hline \multirow[t]{6}{*}{$\mathrm{PN}^{\dagger}$} & $\mathrm{PN}^{\dagger}$ & $\mathrm{F}>\mathrm{P}$ & 7.17 & .015 & .27 & & & \\
\hline & & $\mathrm{C}>\mathrm{F} / \mathrm{P}$ & 7.35 & .014 & .28 & 4.87 & .040 & .20 \\
\hline & & $\mathrm{L}<\mathrm{R}$ & 10.25 & .005 & .35 & 16.93 & .001 & .47 \\
\hline & & $\mathrm{M}<\mathrm{L} / \mathrm{R}$ & & & & 8.12 & .010 & .30 \\
\hline & & $\mathrm{F}>\mathrm{P} \times \mathrm{M}>\mathrm{L} / \mathrm{R}$ & & & & 17.36 & .001 & .48 \\
\hline & & $\mathrm{C}>\mathrm{F} / \mathrm{P} \times \mathrm{M}<\mathrm{L} / \mathrm{R}$ & 6.63 & .019 & .26 & 6.46 & .020 & .25 \\
\hline \multirow[t]{5}{*}{$\mathrm{P} 2 / \mathrm{N} 2 \mathrm{~b}$} & $\mathrm{P} 2 / \mathrm{N} 2 \mathrm{~b}$ & $\mathrm{C}>\mathrm{F} / \mathrm{P}$ & 20.90 & $<.001$ & .52 & 3.70 & .069 & .16 \\
\hline & & $\mathrm{L}>\mathrm{R}$ & 14.79 & .001 & .44 & & & \\
\hline & & $\mathrm{F}<\mathrm{P} \times \mathrm{M}<\mathrm{L} / \mathrm{R}$ & & & & 11.78 & .003 & .38 \\
\hline & & $\mathrm{C}>\mathrm{F} / \mathrm{P} \times \mathrm{L}>\mathrm{R}$ & 3.86 & .064 & .17 & & & \\
\hline & & $\mathrm{C}>\mathrm{F} / \mathrm{P} \times \mathrm{M}>\mathrm{L} / \mathrm{R}$ & 3.55 & .074 & .16 & & & \\
\hline \multirow[t]{4}{*}{$\mathrm{N} 2 \mathrm{c}$} & & $\mathrm{L}<\mathrm{R}$ & 4.98 & .038 & .21 & & & \\
\hline & & $\mathrm{M}<\mathrm{L} / \mathrm{R}$ & 9.43 & .006 & .33 & & & \\
\hline & & $\mathrm{C}>\mathrm{F} / \mathrm{P} \times \mathrm{L}<\mathrm{R}$ & 11.05 & .004 & .37 & & & \\
\hline & & $\mathrm{C}>\mathrm{F} / \mathrm{P} \times \mathrm{M}<\mathrm{L} / \mathrm{R}$ & 11.07 & .004 & .37 & & & \\
\hline \multirow[t]{5}{*}{ P3 } & P3a* & $\underline{\mathrm{F}<\mathrm{P}}$ & 34.95 & $<.001$ & .65 & $\underline{6.02}$ & .024 & .24 \\
\hline & & $\mathrm{C}>\mathrm{F} / \mathrm{P}$ & 42.22 & $<.001$ & .69 & & & \\
\hline & & $\mathrm{M}>\mathrm{L} / \mathrm{R}$ & 44.77 & $<.001$ & .70 & 14.18 & .001 & .43 \\
\hline & & $\mathrm{C}>\mathrm{F} / \mathrm{P} \times \mathrm{L}<\mathrm{R}$ & 5.63 & .028 & .23 & 3.63 & .072 & .16 \\
\hline & & $\mathrm{C}>\mathrm{F} / \mathrm{P} \times \mathrm{M}>\mathrm{L} / \mathrm{R}$ & 11.44 & .003 & .38 & & & \\
\hline \multirow[t]{5}{*}{ SW } & SW & $\mathrm{F}<\mathrm{P}$ & 17.93 & $<.001$ & .49 & 12.26 & .002 & .39 \\
\hline & & $\mathrm{C}>\mathrm{F} / \mathrm{P}$ & 7.44 & .013 & .28 & 7.09 & .015 & .27 \\
\hline & & $\underline{\mathrm{M}<\mathrm{L} / \mathrm{R}}$ & 19.29 & $<.001$ & .50 & $\underline{6.94}$ & $\underline{.016}$ & .27 \\
\hline & & $\mathrm{F}<\mathrm{P} \times \mathrm{M}>\mathrm{L} / \mathrm{R}$ & 50.78 & $<.001$ & .73 & 24.21 & $<.001$ & .56 \\
\hline & & $\mathrm{C}>\mathrm{F} / \mathrm{P} \times \mathrm{M}<\mathrm{L} / \mathrm{R}$ & 33.97 & $<.001$ & .64 & & & \\
\hline \multirow[t]{6}{*}{ LP } & LP & $\mathrm{C}>\mathrm{F} / \mathrm{P}$ & 30.47 & $<.001$ & .62 & 4.39 & .050 & .19 \\
\hline & & $\mathrm{L}<\mathrm{R}$ & 9.79 & .006 & .34 & 5.64 & .028 & .23 \\
\hline & & $\mathrm{M}>\mathrm{L} / \mathrm{R}$ & & & & 5.12 & .036 & .21 \\
\hline & & $\mathrm{F}>\mathrm{P} \times \mathrm{M}<\mathrm{L} / \mathrm{R}$ & 5.33 & .032 & .22 & & & \\
\hline & & $\mathrm{C}>\mathrm{F} / \mathrm{P} \times \mathrm{L}<\mathrm{R}$ & 11.15 & .003 & .37 & & & \\
\hline & & $\mathrm{C}>\mathrm{F} / \mathrm{P} \times \mathrm{M}<\mathrm{L} / \mathrm{R}$ & 4.29 & .052 & .18 & & & \\
\hline
\end{tabular}

Notes: Significant effects are indicated by a bold $p$ value. The reversal of any pair of directional indicators within a single effect is statistically equivalent; e.g., $\mathrm{C}<\mathrm{F} / \mathrm{P} \times \mathrm{L}<\mathrm{R} \equiv \mathrm{C}>\mathrm{F} / \mathrm{P} \times \mathrm{L}>\mathrm{R}$. Underlined statistical results indicate a reversal of the corresponding underlined effect or interaction.

${ }^{\dagger} \mathrm{PN}$ data are assessed at the temporal (F7, T7, P7, F8, T8, P8) and midline (Fz, Cz, Pz) sites.

*The Older P3b is not reported as there were no topographical effects or interactions approaching significance. 
Table 3. Go/NoGo effects in the identified components in the young and older adult groups.

\begin{tabular}{|c|c|c|c|c|c|c|c|c|}
\hline \multirow[b]{2}{*}{ Young } & \multirow[b]{2}{*}{ Older } & \multirow[b]{2}{*}{ Effect } & \multicolumn{3}{|c|}{ Young } & \multicolumn{3}{|c|}{ Older } \\
\hline & & & $F$ & $p$ & $\eta_{\mathrm{p}}^{2}$ & $F$ & $p$ & $\eta_{\mathrm{p}}^{2}$ \\
\hline \multirow[t]{2}{*}{$\mathrm{P} 1$} & P1 & Go $>$ NoGo $\times$ L $>$ R & & & & 17.39 & .001 & .48 \\
\hline & & Go $>$ NoGo $\times$ C $>$ F $/ \mathrm{P} \times \mathrm{L}>\mathrm{R}$ & & & & 19.47 & $<.001$ & .51 \\
\hline \multirow[t]{5}{*}{$\mathrm{N} 1-1$} & N1-1 & Go $>$ NoGo $\times$ C $>$ F/P & 7.83 & .011 & .29 & & & \\
\hline & & Go $>$ NoGo $\times$ L $>$ R & & & & 4.74 & .042 & .20 \\
\hline & & Go $>$ NoGo $\times$ M $>$ L/R & 5.29 & .033 & .22 & & & \\
\hline & & Go $>$ NoGo $\times$ C $>$ F $/ \mathrm{P} \times \mathrm{L}>\mathrm{R}$ & & & & 11.77 & .003 & .38 \\
\hline & & Go $>$ NoGo $\times \mathrm{C}>\mathrm{F} / \mathrm{P} \times \mathrm{M}>\mathrm{L} / \mathrm{R}$ & 4.33 & .051 & .19 & & & \\
\hline \multirow[t]{6}{*}{$\mathrm{PN}^{\dagger}$} & $\mathrm{PN}^{\dagger}$ & Go $>$ NoGo $\times \mathrm{F}>\mathrm{P}$ & 5.81 & .026 & .23 & 4.50 & .047 & .19 \\
\hline & & Go $>$ NoGo $\times C>F / P$ & $\underline{10.77}$ & .004 & .36 & & & \\
\hline & & Go $>$ NoGo $\times$ M $<$ L/R & 27.69 & $<.001$ & .59 & 26.20 & $<.001$ & .58 \\
\hline & & $\underline{\mathrm{Go}}>\mathrm{NoGo} \times \mathrm{F}>\mathrm{P} \times \mathrm{M}>\mathrm{L} / \mathrm{R}$ & $\underline{5.26}$ & .033 & .22 & $\underline{8.31}$ & .010 & .30 \\
\hline & & Go $>$ NoGo $\times$ C $>$ F/P $\times$ M $<$ L/R & 14.26 & .001 & .43 & 6.90 & .017 & .27 \\
\hline & & $\underline{\text { Go }>\text { NoGo }}$ & 21.39 & $<.001$ & .53 & $\underline{11.58}$ & .003 & .38 \\
\hline \multirow[t]{8}{*}{$\mathrm{P} 2 / \mathrm{N} 2 \mathrm{~b}$} & $\mathrm{P} 2 / \mathrm{N} 2 \mathrm{~b}$ & Go $>$ NoGo $\times$ F $>$ P & 3.55 & $\overline{.075}$ & .16 & 54.31 & $<\overline{\mathbf{0 0 1}}$ & .74 \\
\hline & & Go $>$ NoGo $\times$ L $>$ R & 4.76 & .042 & .20 & & & \\
\hline & & Go $>$ NoGo $\times$ M $>$ L/R & 25.15 & $<.001$ & .57 & 15.10 & $<.001$ & .44 \\
\hline & & Go $>$ NoGo $\times \mathrm{F}>\mathrm{P} \times \mathrm{L}>\mathrm{R}$ & 6.55 & .019 & .26 & & & \\
\hline & & Go $>$ NoGo $\times \mathrm{F}>\mathrm{P} \times \mathrm{M}>\mathrm{L} / \mathrm{R}$ & 11.94 & .003 & .39 & 9.42 & .006 & .33 \\
\hline & & $\underline{\mathrm{Go}}>\mathrm{NoGo} \times \mathrm{C}>\mathrm{F} / \mathrm{P} \times \mathrm{L}>\mathrm{R}$ & $\underline{3.80}$ & .066 & .17 & & & \\
\hline & & $\overline{\mathrm{Go}}>\mathrm{NoGo} \times \mathrm{C}>\mathrm{F} / \mathrm{P} \times \mathrm{M}>\mathrm{L} / \mathrm{R}$ & 21.35 & $<.001$ & .53 & 6.83 & .017 & .26 \\
\hline & & Go $>$ NoGo & 16.74 & .001 & .47 & & & \\
\hline \multirow[t]{4}{*}{ N2c } & & Go $>$ NoGo $\times$ C $>$ F/P & 9.87 & .005 & .34 & & & \\
\hline & & Go $>$ NoGo $\times \mathrm{F}<\mathrm{P} \times \mathrm{L}>\mathrm{R}$ & 3.21 & .089 & .14 & & & \\
\hline & & $\underline{\mathrm{Go}}>\mathrm{NoGo} \times \mathrm{F}>\mathrm{P} \times \mathrm{M}>\mathrm{L} / \mathrm{R}$ & $\underline{9.22}$ & .007 & .33 & & & \\
\hline & & $\underline{\text { Go }}>$ NoGo $\times \mathrm{C}<\mathrm{F} / \mathrm{P} \times \mathrm{L}>\mathrm{R}$ & $\underline{3.51}$ & .077 & .16 & & & \\
\hline \multirow[t]{18}{*}{ P3 } & P3a & Go $>$ NoGo $\times \mathrm{F}<\mathrm{P}$ & 105.61 & $<.001$ & .85 & 9.27 & .007 & .33 \\
\hline & P3b & & & & & 5.02 & .037 & .21 \\
\hline & & $\underline{\mathrm{Go}}>\mathrm{NoGo} \times \mathrm{C}>\mathrm{F} / \mathrm{P}$ & $\underline{5.39}$ & .032 & .22 & $\underline{30.72}$ & $<. \underline{001}$ & .62 \\
\hline & & & & & & - & - & - \\
\hline & & Go $>$ NoGo $\times$ L $<$ R & 7.05 & .016 & .27 & 33.86 & $<.001$ & .64 \\
\hline & & & & & & - & - & - \\
\hline & & $\underline{\text { Go }}>$ NoGo $\times M>L / R$ & $\underline{38.77}$ & $<. \underline{001}$ & .67 & $\underline{12.41}$ & .002 & .40 \\
\hline & & & & & & - & - & - \\
\hline & & Go $>$ NoGo $\times$ F $<$ P $\times$ L $>$ R & 6.04 & .024 & .24 & - & - & - \\
\hline & & & & & & 20.11 & $<.001$ & .51 \\
\hline & & Go $>$ NoGo $\times \mathrm{F}<\mathrm{P} \times \mathrm{M}>\mathrm{L} / \mathrm{R}$ & 34.52 & $<.001$ & .65 & - & - & - \\
\hline & & & & & & 8.50 & .009 & .31 \\
\hline & & Go $>$ NoGo $\times$ C $>$ F $/ \mathrm{P} \times \mathrm{L}<\mathrm{R}$ & 16.14 & .001 & .46 & 33.39 & $<.001$ & .64 \\
\hline & & & & & & - & - & - \\
\hline & & $\underline{\mathrm{Go}}>\mathrm{NoGo} \times \mathrm{C}>\mathrm{F} / \mathrm{P} \times \mathrm{M}>\mathrm{L} / \mathrm{R}$ & $\underline{31.20}$ & $<. \underline{001}$ & .62 & $\underline{9.17}$ &.$\underline{007}$ & .33 \\
\hline & & & & & & - & - & - \\
\hline & & $\underline{\text { Go }>\text { NoGo }}$ & $\underline{8.05}$ & .011 & .30 & $\underline{9.10}$ & .007 & .32 \\
\hline & & & & & & - & - & - \\
\hline \multirow[t]{7}{*}{ SW } & SW & $\underline{\mathrm{Go}}>\mathrm{NoGo} \times \mathrm{F}<\mathrm{P}$ & 5.35 & .032 & .22 & $\underline{4.94}$ & .039 & .21 \\
\hline & & $\overline{\mathrm{Go}}>\mathrm{NoGo} \times \mathrm{C}>\mathrm{F} / \mathrm{P}$ & 21.15 & $<.001$ & .53 & 3.05 & .097 & .14 \\
\hline & & Go $>$ NoGo $\times$ L $>$ R & 4.33 & .051 & .19 & & & \\
\hline & & Go $>$ NoGo $\times$ M $>$ L/R & 10.99 & .004 & .37 & & & \\
\hline & & Go $>$ NoGo $\times$ F $<$ P $\times$ L $>$ R & 8.44 & .009 & .31 & 5.69 & .028 & .23 \\
\hline & & Go $>$ NoGo $\times \mathrm{F}<\mathrm{P} \times \mathrm{M}>\mathrm{L} / \mathrm{R}$ & 20.62 & $<.001$ & .52 & & & \\
\hline & & Go $>$ NoGo & 47.02 & $<.001$ & .71 & & & \\
\hline \multirow[t]{5}{*}{ LP } & LP & Go $<$ NoGo $\times$ F $<$ P & 14.57 & .001 & .43 & 6.49 & .020 & .25 \\
\hline & & Go $<$ NoGo $\times$ F $<$ P $\times$ L $>$ R & & & & 16.17 & .001 & .46 \\
\hline & & Go $<$ NoGo $\times \mathrm{F}<\mathrm{P} \times \mathrm{M}>\mathrm{L} / \mathrm{R}$ & & & & 3.11 & .094 & .14 \\
\hline & & $\underline{\mathrm{Go}}<\mathrm{NoGo} \times \mathrm{C}>\mathrm{F} / \mathrm{P} \times \mathrm{L}<\mathrm{R}$ & $\underline{8.61}$ & .009 & .31 & & & \\
\hline & & $\overline{\text { Go }<\text { NoGo }}$ & 8.30 & .010 & .30 & & & \\
\hline
\end{tabular}


Notes: Significant effects are indicated by a bold $p$ value. The reversal of any pair of directional indicators within a single effect is statistically equivalent; e.g., Go $>$ NoGo $\times \mathrm{M}<\mathrm{L} / \mathrm{R} \equiv \mathrm{Go}<$ NoGo $\times \mathrm{M}>\mathrm{L} / \mathrm{R}$. Underlined statistical results indicate a reversal of the corresponding underlined effect or interaction.

${ }^{\dagger} \mathrm{PN}$ data are assessed at the temporal (F7, T7, P7, F8, T8, P8) and midline (Fz, Cz, Pz) sites. 